\title{
CURRENT STATUS OF ASIAN ELEPHANT POPULATION Elephas maximus IN PUMAT NATIONAL PARK REGION, NGHE AN PROVINCE
}

\author{
Nguyen Xuan Nghia ${ }^{1, *}$, Nguyen Tien Dat ${ }^{3}$, Nguyen Xuan Dang ${ }^{1}$, \\ Tran Xuan Cuong', Vo Cong Anh Tuan ${ }^{2}$ \\ ${ }^{1, *}$ Institute of Ecology and Biological Resources, VAST, Vietnam \\ ${ }^{2}$ Management board of Pumat National Park, Nghe An Province \\ ${ }^{3}$ Centre for Resources, Environment and Ecological Resources, VUSTA, Hanoi
}

Received 5 December 2019, accepted 14 April 2020

\begin{abstract}
Asian elephants are under high threats of extinction in Vietnam and worldwide. Population assessment of Asian elephants in Pumat National Park (NP) region, carried out in 2018-2019, showed that the wild Asian elephants population in this region consisted of 3 groups with a total of 13-14 individuals. In Tuong Duong District, a group of 4-5 individuals lived in an area near Canh Ta stream (Tam Dinh commune, Vietnam) and Nam Xi stream (Muong Long commune, Laos), across the border between Vietnam and Laos. The group in Con Cuong district, with only one adult female, lived in forest compartments 780, 781, 789 and 786 of Con Cuong Forestry Company, within the buffer zone of Pumat NP. The group in Anh Son district consisted of 8 individuals (5 adult females, one adult male, one sub-adult male and an juvenile born in 2016). They live in Cao Veu sector of Pumat NP core zone and buffer zone areas consisting of protected forests, rubber plantation forests and agricultural lands of households in Phuc Son Commune (Anh Son District) and Thanh Duc Commune (Thanh Chuong District).

Wild Asian elephants in Pumat NP region are facing dangers of extinction due to their small number as well as direct and indirect threats from human. The elephant group in Anh Son district, with the largest number of individuals consisting of breeding males, breeding females and a calf, is the most important for the maintainance and future development of elephant population within Pumat NP. However, they are facing a number of serious threats such as: uncontrolled wildlife hunting and trade; rapid decrease and degradation of natural forest outside of Pumat NP; and increasingly serious human-elephant conflicts.
\end{abstract}

Keywords: Elephas maximus,biodiversity conservation, endangered species, Asian Elephant, Pumat National Park.

Citation: Nguyen Xuan Nghia, Nguyen Tien Dat, Nguyen Xuan Dang,Tran Xuan Cuong, Vo Cong Anh Tuan, 2020. Current status of Asian elephant population Elephas maximus in Pumat National Park Region, Nghe An Province. Academia Journal of Biology, 42(2): 55-64. https://doi.org/10.15625/2615-9023/v42n2.14668.

*Corresponding author email: nghiaiebr@gmail.com

(C2020 Vietnam Academy of Science and Technology (VAST) 


\section{INTRODUCTION}

The Asian elephant, Elephas maximus was once distributed almost throughout Asia.However, its current natural distribution is confined to only 13 countries with a total number of about 40,000 individuals. For many reasons, this species is under high threats of extinction (IEF 2017). The IUCN Red List of Threatened Species (IUCN 2019) has classified the Asian elephant as Endangered (EN) and the Convention on International Trade of Endangered Species (CITES) has listed Asian elephant in Appendix I with a strict ban on use and international trade for commercial purposes. Conservation of Asian elephants becomes now an urgent issue in the World, especially in their native countries, including Vietnam.

The population in Vietnam has been seriously reduced and is now facing high dangers of extinction. Red Book of Vietnam (Ministry of Science and Technology, Vietnam Institute of Science and Technology 2007) has placed the Asian elephant at the highest threat level-Critically Endangered (CR). Decree No. 06/2019/ND-CP of Vietnam Government listed the Asian elephant in the National List of Precious, Rare and Endangered Species of Conservation Priority.

According to recent studies by Nguyen Xuan Dang (2015) and Vietnam Forestry Department (2018), there currently remain only about 100-130 wild elephants in Vietnam, scattered in 8 provinces ranging from Son La to Dong Nai Province with most of groups having 1-5 individuals. These groups are isolated from each other and have unbalanced sex ratios and age structures. Meanwhile, the threats to their survival, including illegal hunting, trade of elephant parts, habitat loss and degradation, increase of human-elephant conflicts, etc. are widespread and uncontrolled. For the urgent protection of this species from extinction, in 2013, Vietnam Government has approved the "Masterplan of conservation of the Asian elephant in
Vietnam, period 2013-2020" (Decision No. 763/QD-Ttg, dated 21 May 2013 of PrimeMinister), which outlined strategic measures for conserving Asian elephants in Vietnam including the designation of three areas containing more than 10 individuals with breeding capacity for priority conservation The three areas are Pumat National Park (NP) in Nghe An Province, York Don NP-Ia Lop Forestry Company in Dak Lak Province and Cat Tien NP - Dong Nai Nature and Culture Reserve in Dong Nai Province.

Pumat NP, located in the South-West of Nghe An Province, along the Vietnam-Laos national border, covered the territory under administration of Anh Son, Con Cuong and Tuong Duong districts. Previous studies reported about 2-3 groups of wild elephants living in the core zone and buffer zone of Pumat NP (Walston et al., 1996, Dawson et al., 1997, Trinh Viet Cuong et al., 2000, SFNC 2001, Nguyen Xuan Dang et al., 2005, Nguyen Xuan Dang, 2015). However, little is known about their group structure and activity areas. The "Project for urgent conservation of Elephants in Nghe An Province until 2020" of Nghe An People's Committee, approved by Decision No.4796/QĐ-UBND dated 13 October 2013, reported 3 elephant groups of about 13-14 individuals living in Pumat NP region. However, this source of data came from quick village interviews with low accuracy and lacked information on group structure and activity area. Recognizing this fact, the Project put "conducting field surveys to identify size and structure of each elephant group and monitoring their activity change" as an important measure of elephant conservation strategies in the 2013-2020 period. Unfortunately, due to lack of financial support, this task could not be implemented from the beginning of the project period.

In order to create a solid scientific basis for developing measures for conservation of the elephant population in Pumat NP region, during 2018-2019, we conducted studies on the group structure and activity areas of this elephant population. 


\section{MATERIALS AND METHODS}

Study area and survey areas

The study area covers both core zone (94,805 ha) and buffer zone (50,000 ha) of Pumat NP and adjacent parts (about 10,000 ha) of Thanh Duc and Thanh Son communes in Thanh Chuong district, Nghe An Province, bordering Laos on the western side. The terrain is deeply intersected by steep slopes and narrow valleys. Average steepness in the region is of $25-35^{\circ}$ and elevation ranges from $100 \mathrm{~m}$ to $1,841 \mathrm{~m}$ asl. (Pumat mountain peak), while about $90 \%$ of the territory is below 1,000 m asl. Flat areas are very limited and mostly occupied by human settlements and agricultural lands. The area has a complex river and stream system, that provides abundant surface water year-round. The core zone of Pumat NP is covered by mountain broad-leaved evergreen forests, mainly of rich and medium status. While in the lowland valleys, mixed timber-bamboo forests dominate. In the buffer zone and its vicinity, the dominating forests are poor secondary broad-leaved evergreen forests, restored forests, mixed timber-bamboo forests and artificial plantations.

Due to very large size of the study area, elephant surveys could only be conducted in selected areas. Selected areas must be located within potential activity area of elephant groups, based on previous surveys and updated database of Pumat NP Management Board. The selected survey areas are Tam Quan, Tam Dinh, Tam Thai, Tam Hop, Xa Luong communes of Tuong Duong district; Chau Khe, Chi Khe, Luc Da communes of Con Cuong district; Phuc Son communes of Anh Son district; Thanh Duc and Thanh Son communes of Thanh Chuong district (Fig. 1).

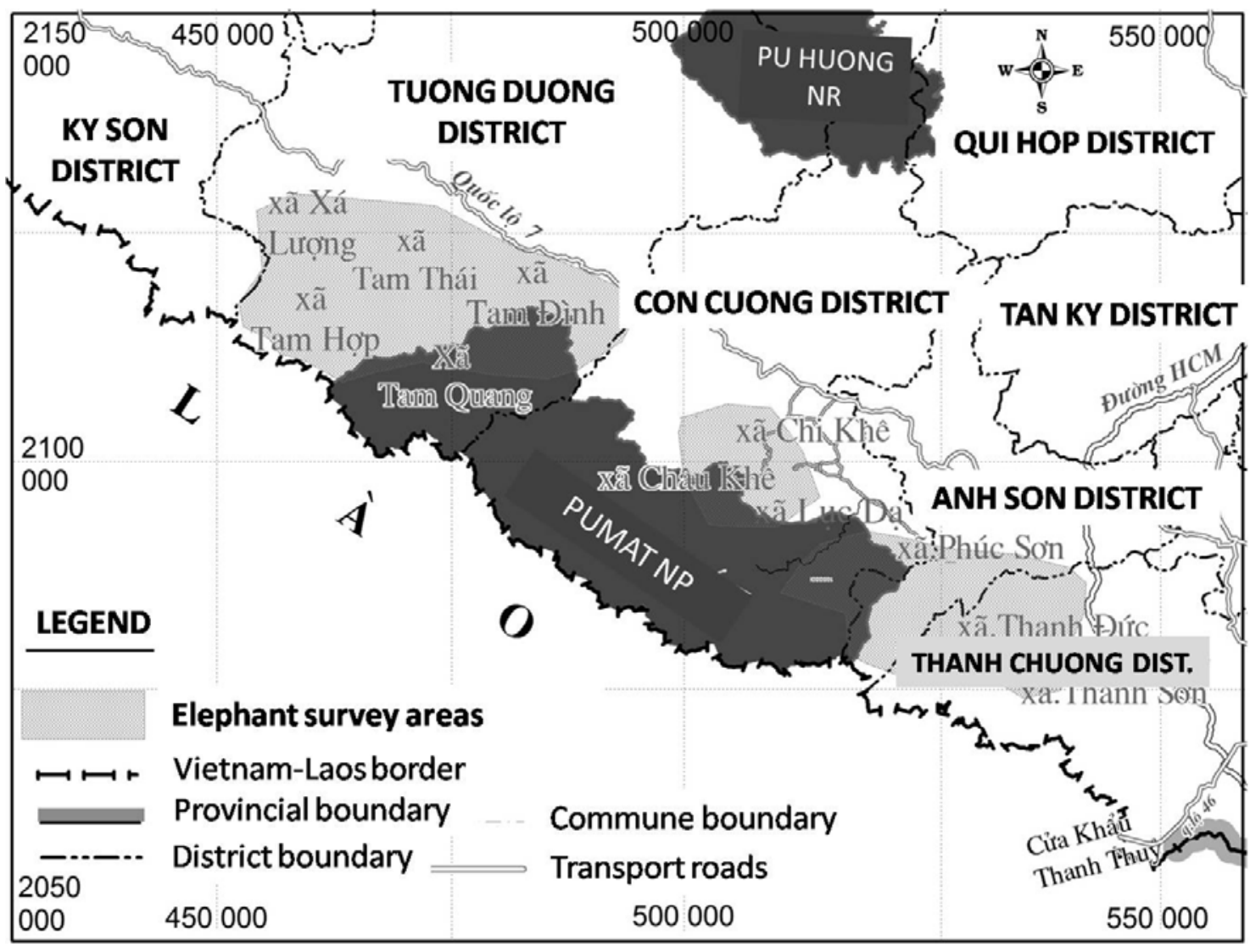




\section{Study period and methods}

Figure 1. Location of elephant survey areas [Map source:Pumat NP]

From 2018 to 2019, six surveys were conducted in April 2018, August 2018, December 2018, March 2019, August 2019 and October 2019. Each survey lasted 10-12 days, totaling 66 field-working days. Besides, 20 continous monitoring camera-traps were also placed in Cao Veu area of Pumat NP and Anh Son Protection Forest (Anh Son District) from 9 April to 5 November 2018.

Data were collected as follows:

Semi-structured interview with local residents and forest protection officials: Many villagers in study area were interviewed including Mr. Lo Van Ngoc in Poong Village, Tam Hop Commune, Mr. Xong Ba Ly in Huoi Son Village, Tam Hop Commune, Mr. Le Van Duc (57 years old) in Tung Huong Village, Tam Quang Commune, and Mr. Nguyen Ngoc Dong in Cao Veu 1 Village, Phuc Son Commune. The interviewed forest protection officials include forest rangers of Pumat NP, as well as forest guards of Anh Son Protection Forest, Thanh Chuong Protection Forest, Con Cuong Forestry Company and Tuong Duong Protection Forest. During the interview survey, the survey team also collected available elephant-related materials such as photographs of elephant groups, videoclips of elephant activity, etc. In total, 176 local residents and 22 forest protection officials were interviewed.

Transect survey method: A system of survey transects was established in survey areas based on results of the interview survey, updated elephant database of Pumat NP, and current vegetation and topographic maps of the study areas. The transects covered all forest and elephant habitat types within potential elephant areas. Each transect is 2-12 $\mathrm{km}$ long. Due to very complicated terrain and dense vegetation, available trails and patrolling trails of forest rangers were used as main transects. From the main transects, a number of side transects to locations with high potentials to be visited by elephants (feeding areas, salt-licks, water sources, etc.) were chosen. There were 12 main transects and about $80 \mathrm{~km}$ of transect length were surveyed. During the transect survey, group size, sex and age structure of sighted elephant group were recorded: (following Varma et al., 2012). For observed signs of elephant activities, circumference, width and length of hind footprints and circumference of dung piles were measured (following Varma et al., 2008). Signs of feeding, drinking, body rubbing were also recorded. Habitat type and status were described. GSP coordinates and photographs of elephants and their signs were taken when sighted. Evidences of threats to elephants and their habitat observed during the survey were recorded as well.

Camera-trapping method: In order to identify the population structure of the largest elephant group in Pumat NP region, $20 \mathrm{HCO}$ ScoutGuard SG560C camera-traps were placed in Cao Veu area of Pumat NP and Anh Son Protection Forest from 4 September to 5 November 2018. The camera-traps were firmly tied to trees at $1.2 \mathrm{~m}$ above ground and put in continuous monitoring mode. The camera-traps were checked twice (in 5 October 2018 and 5 November 2018) to download to data and replace the batteries. During this survey, 2 camera-traps stopped working few days after being placed in the forests.

We also used images of elephants from videoclips taken in 2015 by Mr. Nguyen Ba Lam (from the Twelfth September Rubber Plantation Enterprise in Thanh Duc Commune, Thanh Chuong District) and elephant pictures taken by Mr.Luong Van Su (Cao Veu 4 Village) in 2018 in Suc Stream near Cao Veu 1 Village.

\section{RESULTS AND DISCUSSION}

\section{Activity area and structure of each elephant groups}

Data of this interview survey and field investigation indicate the presence of three elephant groups in Pumat NP region. They live in isolated areas (figure 2) in Tuong Duong District, Con Cuong District and AnhSon District. 


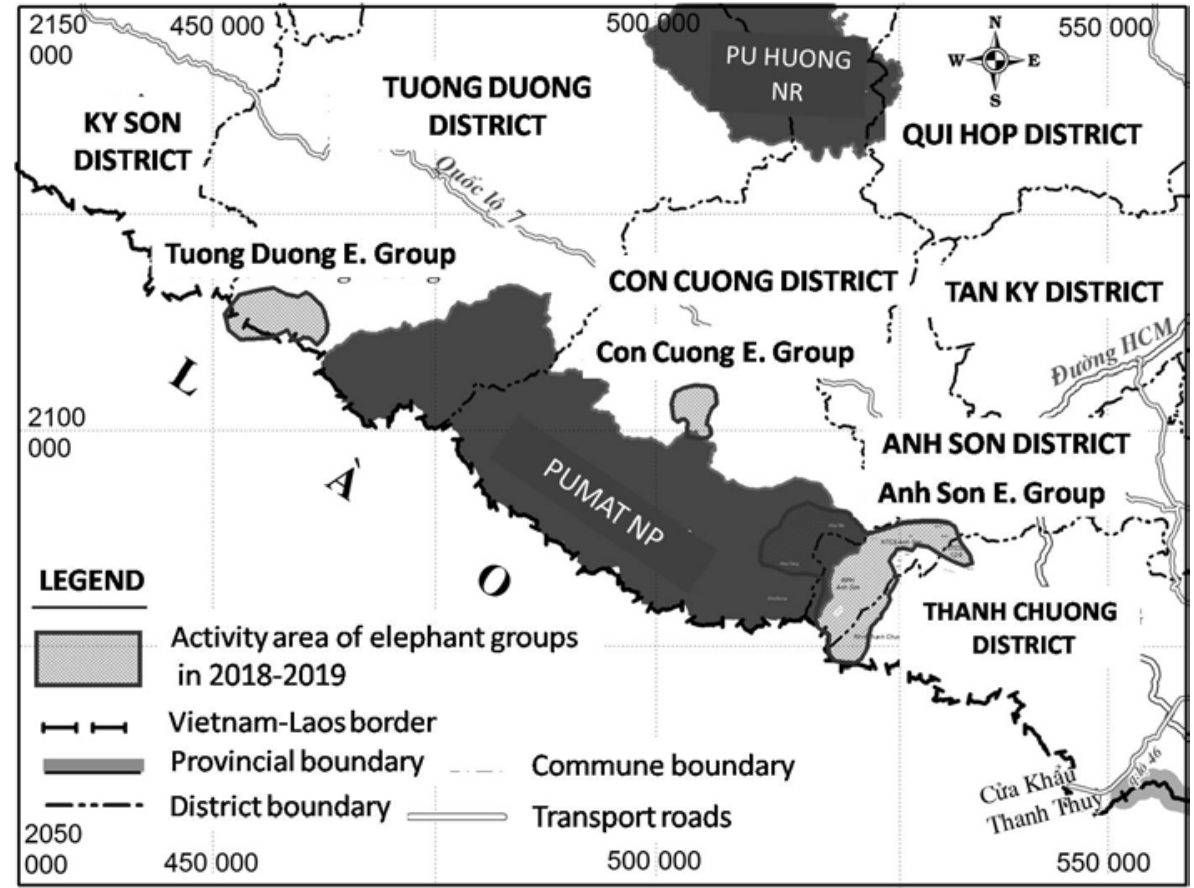

Figure 2. Activity areas of the 3 elephant groups during 2018-2019 [Map source: Pumat NP]

\section{Tuong Duong Elephant Group}

The Tuong Duong elephant group has been recorded in previous studies by Dawson et al. (1997), Do Tuoc (1998), Trinh Viet Cuong et al. (2000), SFNC (2001) and Department of Agriculture and Rural Development of Nghe An Province (Nghe An DARD) (2013). Data from these studies showed that before 2010, this elephant group consisted of at least 5 individuals including 1 adult male, one adult female, one sub-adult male and 2 juveniles. This group lived in a part of Pumat NP core zone belonging to Tam Quang commune (Pulon mountain, upper part of Khe Thoi and Khe Mat streams, Hong Quang slope near $\mathrm{Pu}$ Xam Liem mountain). Sometimes, they moved to territories of Tam Quang, Tam Dinh, Tam Thai, Tam Hop and Xa Luong communes in buffer zone of Pumat NP. During the 1998-2004 period, using camera-traps, the Social Forestry and Nature Conservation Project of Nghe An Province (SFNC) obtained pictures of 4 elephants from this group (one sub-adult male, one adult female and 2 juveniles of unknown sex) in upper part of Khe Thoi and Khe Mat streams
(Tam Quang commune). Mr. Le Van Duc (57 years old) from Tung Huong village, Tam Quang commune, who used to work as a field guide for the SFNC camera-trapping team, informed us that during that time, he often observed footprints of an elephant mother and her baby in Khe Thoi up-stream. This indicates that this elephant group should have an adult male and therefore, the group should consist of at least 5 individuals. Possibly, because the adult male travelled separately and far away from the group, local residents could not see him.

In this study, we also interviewed residents of Tam Quang, Tam Thai, Tam Dinh, Tam Hop and Xa Luong communes in Tuong Duong district. As reported by many interviewees, before 2010, elephant tracks were often seen in upper part of Khe Thoi, Khe Mat streams (Tam Quang commune) and Canh Ta stream (a branch of Cha La stream) in Tam Hop commune. During the 2009-2010 period, a mother and his baby often travelled in an area near the Pulon mountain (Tam Dinh commune), Han stream (Tam Thai commune) and La Van stream (Tam Hop commune). In 
2009/2010, a group of 4-5 elephants destroyed a rice field and a rice granary of Mr. Lo Van Bien's household near La Van stream (Xop Nam village, Tam Hop commune). In 2012, an adult male was killed near Vang Mon village (Tam Hop commune). However, from 2012 to now, this elephant group did not appear in this area any more. Our field investigation in upper part of Khe Thoi, Khe Mat stream and forests around Dooc Bua village (Tam Thai commune), Xop Nam village (Tam Hop commune) did not find any evidence of this elephant group.

Many local residents informed us that this elephant group had moved to an area along Vietnam-Laos border (approximate coordinates: 461.525/108.870, VN2000) belonging to Canh Ta stream (Tam Hop commune, Vietnam) and Nam Xi stream (Muong Long village, Vien Thoong District, Bolikhamxay Province, Lao PDR). Interviewees from Tam Hop commune reported that during 2010-2015, elephant tracks and dung piles of about 4-5 elephants were often seen in this are. However, no new signs of elephants have been observed since 2015. In 2018, Pumat NP management board interviewed the Laotian forestry team and it was known that the elephant group still existed in this area but its group size and structure was un-known (Vo Cong Tuan Anh 2018, pers, communication). Because, the Canh Ta-Nam Xi stream area is located very far from our campsite and belongs to strictly controlled frontier area, we could not come to this area for field investigation.

\section{Con Cuong Elephant Group}

The Con Cuong elephant group has been reported in several previous surveys such as Dawson et al. (1997), Do Tuoc (1998) and SFNC (2001). However, there is little information on the group structure and activity area range. The "Project of urgent conservation of elephants in Nghe An Province until 2020" (Nghe An DARD, 2013) reported that this group consisted of 3 individuals (1 mother, 1 baby and 1 juvenile of un-known sex). They often travel in Khe $\mathrm{Bu}$ and Khe Choang areas in the core zone of Pumat NP. In 2009, a mother and her baby appeared in Khe Nong stream area (a branch of Khe Bu stream) of Chau Khe Commune in the buffer zone of Pumat NP. They destroyed agriculture fields and field houses of Nong and Bu villages, and Met plantation (Dendrocalamus barbatus) of Con Cuong Forestry Company.

Interview surveys in Chau Khe, Chi Khe, Luc Da communes and forest ranger stations of Pumat NP show that in Khe Bu - Khe Choang area, signs of the elephant activity had not been observed for several years. Meanwhile, a single adult male is found living in Thac Kem waterfall area belonging to forest compartments 780, 781, 789 and 786 of Con Cuong Forestry Company. This elephant often destroys Met plantation (Dendrocalamus barbatus) and many road signs along the road to Thac Kem waterfall tourism site. Our field investigation in this area found several fresh tracks and dung piles of elephant. The measurements of these tracks (circumference: 120-134 cm, length:39-42 cm, width: 37-40) indicated an adult elephant. Elephant pictures taken by forest rangers from Thac Kem Ranger Station showed that it was an adult female.

\section{Anh Son Elephant Group}

Many reports and publications of previous surveys mentioned the existence of the Anh Son elephant group (Walston et al., 1996; Dawson et al., 1997; Do Tuoc 1998; Trinh Viet Cuong et al., 2000; SFNC, 2001; Nghe An DARD,2013). However, there was very little information about the group structure and its activity area range. According to Nghe An DARD (2013), this elephant group consisted of at least 5 individuals (2 adult females, 1 juvenile male, and 2 sub-adult individuals of un-known sex). One adult male of this group was killed in 2011, in Phuc Son Commune (Anh Son district). This elephant group lives in Cao Veu area belonging to Pumat NP core zone and Anh Son Protection Forest and often expand their activity area into Pumat NP buffer zone belonging to Anh Son Forestry 
Company in Phuc Son commune where it caused severe human-elephant conflict.

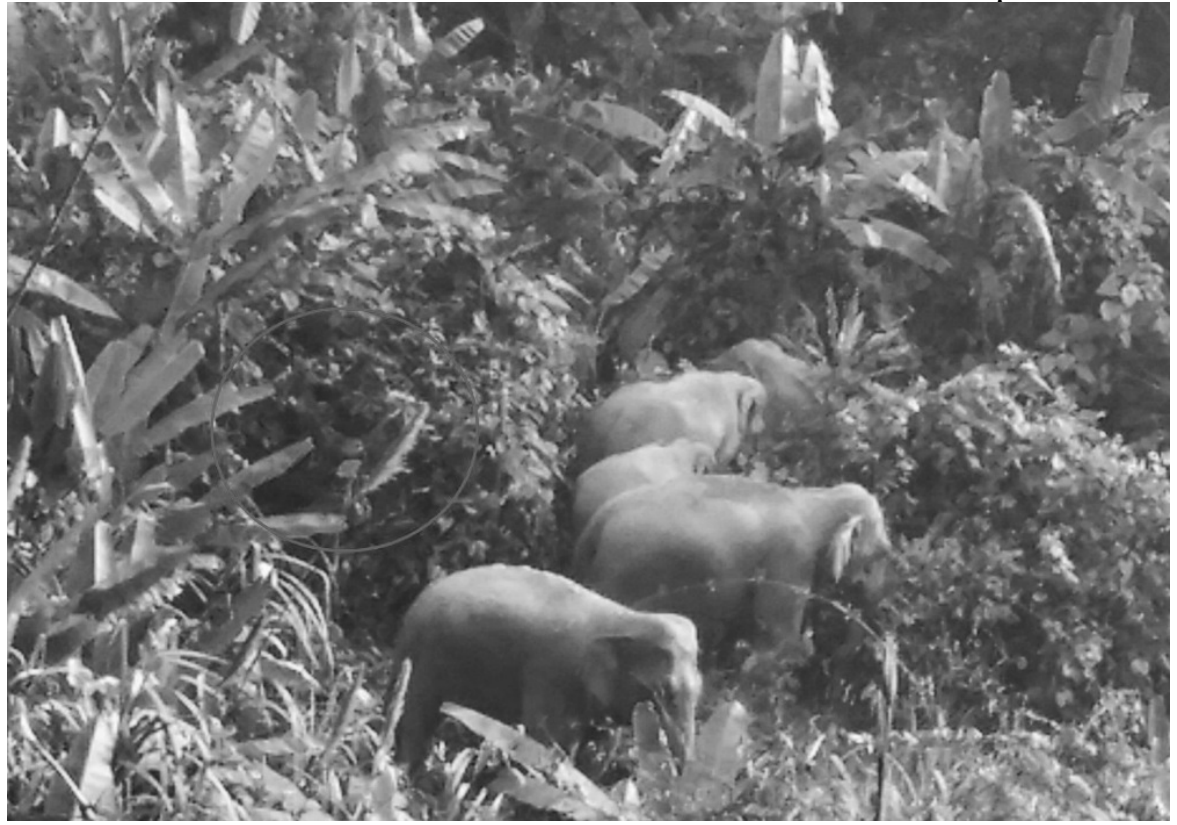

Figure 3.A part of Anh Son elephant group. Picture taken in 13 February 2018 by Mr. Luong Van Su, a local villager

Our survey in 2019 has obtained important information about Anh Son elephant group. Results from interviewing local residents and forest rangers showed that this elephant group consisted of 7-8 individuals including 1 subadult male and a baby of about 2 years old. We consulted videoclips taken by a worker on $23^{\text {rd }}$ of May 2015, in the Twelfth September Rubber Plantation Enterprise and pictures taken by a local resident in $13^{\text {th }}$ of February 2018 at Suc stream area near the Cao Veu 1 villager (Figure 3). The videoclips recorded 5 individuals including 3 adult females, 1 young male of about 3-4 years old and 1 juvenile of un-known sex. While the pictures recorded 6 individuals including 5 adult females and 1 young of about 4-5 years old. Although both videoclips and pictures did not record adult male, local residents reported of an adult male with tusks $30-40 \mathrm{~cm}$ long. Local residents also reported of a female giving birth in October 2016, in Met plantation of Mr. Nguyen Ngoc Dong household (Cao Veu 1 village, Phuc Son commune). After the birth, the mother and her baby stayed in the Met plantation for several months and then moved to Veu stream area in Anh Son Protection Forest. These evidences indicated the existence of an adult male in the Anh Son elephant group.

During our field investigation, we did not get direct sightings of the elephants. However, we found many old and fresh tracks, eating signs, dung piles and body-rubbing signs in natural forests of Anh Son Protection Forests, forest plantations and agricultivation lands of local agriculture farms and households. Measurement data showed that the footprints were from adult and sub-adult elephants (circumference of $112-136 \mathrm{~cm}$, width of 31-39 $\mathrm{cm}$ and length of 36-42 cm). In Dzoc Tien stream area of Anh Son Protection Forest $\left(18^{\circ} 45^{\prime} 42^{\prime \prime} \mathrm{B}, 104^{\circ} 55^{\prime} 14^{\prime \prime} \mathrm{N}\right)$, we found footprints of the young elephant born in 2016 (44 cm in circumference, $15 \mathrm{~cm}$ in width and $14 \mathrm{~cm}$ in length). The camera-trapping survey obtained 56 elephant images on $21^{\text {st }}$ of October 2018 in Anh Son Protection Forest, of which 3 pictures are of an adult male with tusks about 30-40 cm long. Thus, our survey data 
confirmed that the Anh Son elephant group had 8 individuals including an adult male.

Our study also indicated that the current activity area of Anh Son elephant group covered Cao Veu sector of Pumat NP (Khe Tang, Khe Bung and Khe Yen streams), entire area of Anh Son Protection Forest and a part of Thanh Chuong Protection Forest, Anh Son Rubber Plantation Enterprise, the Twelfth September Rubber Plantation Enterprise and agricultural lands of local villages (Cao Veu 1, Cao Veu 2, Cao Veu 3, Cao Veu 4, Coi, Bai Lim, Bai Da villages of Phuc Son commune, Anh Son district and theThird February Village of Thanh Duc commune, Thanh Chuong district. The current activity area is estimated to total 18,000 ha. The elephants stay mostly in territory of Anh Son Protection Forest because the habitat here is the most suitable for them (not too high or too steep terrain, rich surface water source, rich food resources provided by secondary forests, mixed timber-bamboo forests and open grasslands).

\section{Problems of elephant conservation in Pumat NP region}

Results of our study in 2018-2019 showed that, at present, the elephant population in Pumat NP region consisted of 3 groups with a total of 13-14 individuals.This is a very small population and all groups are isolated each other.Therefore, the population is at high risk of degradation/extinction.The Con Cuong group, now having only a single adult female, can not develop in the future. Feasibility study on introducing a breeding male or translocating this female to another group with breeding males should be conducted as soon as possible. World experience on elephant translocation can be used to plan this action. The Tuong Duong elephant group is estimated to have $4-5$ individuals, however its sex ratio is unknown. The adult male was killed in 2010, and there is no evidence of another adult male occurrence in this group. Hopefully, this group can communicate with elephants in Laos to give birth and increase its size. More field investigations are needed to determine the group structure and breeding capacity of this group.

The Anh Son elephant group is the most important for maintaining and developing the elephant population in Pumat NP region as it has the highest number of individuals (8 individuals), consisting of both breeding males, females and sub-adult individuals. It is very likely that if this group is well protected, more elephants will beborn and the group will develop. Unfortunately, this group is now facing many severe threats. Wildlife hunting still occurs in the group's activity area. Natural forests outside Pumat NP has been severely reduced and degraded due to conversion into industrial plantations (rubber trees, Acacia, bamboo, etc.) and agricultural cultivation lands. In addition, human-elephant conflicts have become more and more serious, making many local residents stop their support of elephant conservation efforts.

\section{CONCLUSION}

The wild elephant population in Pumat NP region now consists of 3 groups with a total number estimated about 13-14 individuals. Out of 3 groups, 2 groups (in Con Cuong and in Anh Son districts) were confirmed, while the group in Tuong Duong District need more field investigation to determine its structure. Having 8 individuals with all breeding males, females and sub-adults, the Anh Son elephant group plays the most important role in maintaining and developing the wild elephant population in Pumat NP region. Un-controlled wildlife hunting, habitat loss and degradation, and increase of human-elephant conflicts are the main threats to the elephant population.

Acknowledgements: This study was cofunded by Institute of Ecology and Biological Resources (Vietnam Academy of Science and Technology), Project of urgent conservation of elephants in Nghe An Province until 2020, and WWF-Vietnam. The authors would like to express their sincere thanks to leaders of Institute of Ecology and Biological Resources, Management boards of Pumat NP, Anh Son, Tuong Duong and Thanh Chuong Protection 
Current status of Asian elephant population

Forests, Con Cuong Forestry Company, local authorities, local residents and forest guards for their permissions and for providing favorable conditions for us to implement this study. Our special thanks are to Mr. Nguyen Ba Lam from the Twelfth September Rubber Plantation Enterprise and Mr. Luong Van Su from Cao Veu 4 village for allowing us to use their valuable videoclips and elephant photos.

\section{REFERENCES}

Dawson S., Do Tuoc, 1997. Status of Elephants in Nghe An and Ha Tinh Provinces, Vietnam. Gajah 17: 23-25.

Decision No. 763/QD-TTg, dated 21 May 2013 of Prime Minister approving the General Project of Elephant Conservation in Vietnam, Period 2013-2020 (in Vietnamese).

Decision No.4796/QD-UBND, dated 19 October 2013, of the Nghe An Provincial People Committee on approving Project of Urgent Conservation ofElephants in Nghe An Province toward 2020 (in Vietnamese).

Decision No. 160/2013/ND-CP, dated 12 November 2013 of the Government on criteria for identification and management regulations of species belonging to the list of endangered, rare and precious species of conservation priority (in Vietnamese).

Decision No. 06/2019/ND-CP, dated 22 January 2019 of the Government on the management regulations of forest endangered, rare and precious species and implementation of CITES. (in Vietnamese).

Department of Agriculture and Rural Development of Nghe An Province, 2013. A project of an urgent conservation of Elephants in Nghe An Province towards 2020. Nghe An Province, 74 pp. (in Vietnamese).

Do Tuoc, 1998. The present status of the Asian ElephantElephas maximus in Vietnam 1997-1998. In: Proceedings of the conference: Conservation of Asian
Elephants in Indochina, Hanoi, Vietnam, 24-27 ${ }^{\text {th }}$ November 1998 (Eds: Osborn F.V., Vinton M. D.), FFI in Hanoi, 34-42.

IEF, 2017. Asian Elephant Range State Meeting: A final Report. Jakarta, Indonesia, April 18-20, 2017. International Elephant Foundation and IUCN/SSC Asian Elephant Specialist Group, 68 tr.

IUCN, 2019.The IUCN Red List of Threatened Species. https://www.iucnredlist.org/species/7140/ 12828813 Downloaded on 01 December 2019.

Ministry of Science, Vietnam Institute of Science and Technology, 2007. Vietnam Red Data Book. Part 1. Animals. Natural Science and Technology Publisher, Hanoi, 315 pp. (in Vietnamese).

Nguyen Xuan Dang, Trinh Viet Cuong, 2005. Current status of Asian Elephant Elephas maximus in Vietnam and the conservation recommendations. In "Scientific Reports on Ecology and Biological Resources", the proceedings of the first National Scientific workshop,Hanoi, July $15^{\text {th }}$, 2005. Agriculture Publisher, Hanoi, 308-313 (in Vietnamese).

Nguyen Xuan Dang, 2015. An overview of conservation status of wild Asian Elephant Elephas maximus in Vietnam. A technical report for WWF-Vietnam, Hanoi, 59 pp.

SFNC,2001. Pu Mat: the biodiversity survey in a protected area of Vietnam. Social Forestry and Nature Conservation Project (SFNC). Labor and Social Publisher, Hanoi, 1974 pp.

Trinh Viet Cuong, HeffermanJ., Do Tuoc, Ngo Van Tri, F. Momberg, 2000. Vietnam national elephant status review 2000. FFIIndochina Programme, Hanoi, 57tr.

Varma S., Nguyen Xuan Dang, Tran Van Thanh and R. Sukuma 2008. The elephants Elephas maximus of Cat Tien National Park, Vietnam: Status and 
conservation of a vanishing population. Oryx, 42(1), 92-99 doi:10.1017/S0030605308010090.

Varma S., Baskaran N., Sukumar R. (2012). Field Key for Elephant Population Estimation and Age and Sex Classification. Indian Institute of Science, India, $29 \mathrm{pp}$.

Vietnam Forestry Department, 2018. Report on the results of implementation of the
Vietnam Elephant Conservation General Project approved by Decision No. 763/QDTtg, dated 21 May 2013, of PrimeMinister, Hanoi, 20 pp. (in Vietnamese).

Waston J., Do Tuoc, Trinh Viet Cuong, 1996. Assessment of human-elephant conflict in Vietnam: Nghe An Province. FFI, MARD, Hanoi. 